\title{
Seismic Response Mitigation of a Long-Span Tower Bridge with Two Types of Constraint System
}

\author{
Li Xu $\mathbb{D},{ }^{1}$ Qingfei Gao $\mathbb{D}^{2},{ }^{2}$ Junhao Zheng $\mathbb{D}^{1},{ }^{1}$ Chuanhui Ding $\mathbb{D},{ }^{1}$ and Kang Liu $\mathbb{D}^{1}$ \\ ${ }^{1}$ School of Civil Engineering, Fuzhou University, Fuzhou 35018, China \\ ${ }^{2}$ School of Transportation Science and Engineering, Harbin Institute of Technology, Harbin 150090, China \\ Correspondence should be addressed to Li Xu; fzucivilxuli@fzu.edu.cn
}

Received 18 September 2020; Revised 14 October 2020; Accepted 23 October 2020; Published 17 November 2020

Academic Editor: Yi Zhang

Copyright (c) $2020 \mathrm{Li} \mathrm{Xu}$ et al. This is an open access article distributed under the Creative Commons Attribution License, which permits unrestricted use, distribution, and reproduction in any medium, provided the original work is properly cited.

\begin{abstract}
The stress of the main tower of a cable-stayed bridge depends on the connection type between the tower and deck. In order to study the most suitable longitudinal damping mode for a long-span cable-stayed bridge. In this article, a nonlinear finite element model is established based on a large span concrete cable-stayed bridge with a main span of $680 \mathrm{~m}$. Without considering the influence of the transverse constraint, the damping effect of the elastic connection device and the viscous damper is simulated when the longitudinal seismic load is input. The results show that the stiffness of the main beam is increased by installing the elastic connection device, so the longitudinal drift frequency of the main beam is increased, but the stiffness of the structure is not changed by installing the viscous damper. Both viscous dampers and elastic connection structures can reduce the longitudinal displacement of the beam end, but viscous dampers are more favorable for the stress of the main tower. In terms of damping effect, viscous dampers are more suitable for long-span cable-stayed bridges, but, in terms of economy and parameter control, elastic connection devices have more advantages.
\end{abstract}

\section{Introduction}

With the maturity of bridge construction technologies in the past decades, cable-stayed bridges with different main girder types, such as concrete girder and steel girder, have been widely adopted around the world, with a main span possibly reaching over 1000 meters. In the presence of a large number of longspan cable-stayed bridges, the seismic performance of these bridges has raised great concern in the engineering community due to the bridge seismic vulnerability. The half-floating system is widely used in the longitudinal direction (i.e., additional damping devices at the girder-tower connection). Thus, the seismic effect of this system depends on the deformation capacity as temperature rises and the sufficient displacement capacity at ground motions $[1,2]$. Over the past decade, many experimental tests were carried out to develop the constraints for long-span cable-stayed bridges in the longitudinal direction. Alternative vibration control systems to dissipate the input energy were proposed and have been widely used (e.g., the passive control system, the semiactive control system, and the active control system). Among these three systems, the passive one has been widely used. Among the typical passive control systems, the viscous damper (VD) [3] and elastic connecting devices (ECDs) [4] can effectively reduce both the vibration response and the structural displacement of long-span bridges under seismic actions. They may also reduce the internal force at the key sections of bridges, which make them feasible to apply in long-span bridges.

For floating or semifloating systems, on the other hand, the advantage is that the internal force of the main tower is relatively smaller under the seismic action; however, they are more likely to suffer from a large displacement at the girder end. This is especially the case for long-span bridges where the girder-end displacement is even greater. As such, how to take effective measures to control the girder-end displacement of floating or semifloating cable-stayed tower bridges has gained much research interest.

1.1. Application of VD in Cable-Stayed Bridge. Dampers can be divided into different types due to their principle of 
energy dissipation (i.e., lead extrusion dampers, steel dampers, friction dampers, VDs, and others.) The most widely used one for cable-stayed bridges is the VD [5]. Named as such, the damping force of a VD is generated by the viscous fluid in the damper through the orifice. To ensure the satisfactory performance of a damper, the fluid material inside should meet the following requirements: (1) it has strong viscosity and low-temperature sensitivity; (2) it is with strong chemical stability; (3) it is nonflammable, involatile, nontoxic, and of low compressibility.

Many hysteretic models have been available in the literature that can reasonably describe the mechanical properties of a VD. The most representative one is the Maxwell model $[6,7]$ which simplifies the damper into a damping element and a spring element. Ruangrassamee and Kawaskima [8] investigated the seismic effect of the nonlinear viscous damping force scheme and the two-step friction damping force scheme by the benchmark. The result shows that nonlinear viscous dampers have better effective control response with less damping force capacity. Zhu et al. [9] investigated the effect of VDs for cable-stayed bridges under randomly generated earthquake excitation and discussed the two key parameters $\mathrm{C}$ (damping coefficient) and $\alpha$ (damping exponent) by simplifying the VD to Maxwell Model. The result shows that nonlinear VD has better performance in reducing the seismic response of the cablestayed bridge compared to linear VD. The use of VDs on cable-stayed bridges has been discussed in some previous works. Ferreira and Simoes [10] investigated four different techniques including no control, VDs, and VDs with passive and semiactive tunes mass dampers, and the effect of passive dampers and a hybrid control system consisting of passive viscous dampers installed in parallel with semiactive dampers was investigated by the analytical pulses model and 44 recorded near-field ground motions [11]. The numerical simulation results show that the passive VDs can reduce force demand during strong earthquakes. The parameter sensitivity of VDs is analyzed by the nonlinear time history method [12]. The control effect of viscous dampers installed between tower and girder on mitigating the longitudinal vibration of the girder induced by train braking or running is studied. It is shown that the viscous dampers installed between the tower and girder can effectively mitigate the seismic responses of the structure and reduce the longitudinal vibration of the girder and the dynamic responses of towers induced by train braking or running.

The above literature review demonstrates that as a useful energy-dissipation and damping device, VDs can effectively control the seismic effect of tower bridges and reduce the structural displacement + response. They can also reduce the internal force at the key sections of a bridge and have different effects under different types of earthquakes.

1.2. Application of ECDs in Cable-Stayed Bridges. The ECDs installed between the tower and the girder have also been used to reduce the seismic response of cable-stayed bridges. When the stiffness of the ECDs is suitable, the strength and deformation ability of the bridge and girder can be taken into account [13], but the ability to control the displacement of the main beam is very limited [14]. Among them, elastic cables and laminate rubber bearing are widely used. Ali and Abdel-Ghaffar [15] investigated the use of laminate rubber bearing between towers and girders for seismic mitigation. The result showed that, compared with the case with no mitigation device installed, the ECD can effectively reduce the longitudinal displacement at the girder end but may also increase the base shear force and moment at the tower. Wesolowsky and Wilson [16] analyzed the seismic mitigation effects of ECD under near-field earthquakes. It was shown that the ECDs installed between the tower and girder are effective for reducing girder-end displacements. The seismic response of ECDs and VDs was compared. And the effect of the hybrid application of ECDs and VDs on longitudinal seismic response had been compared [17]. The results show that the hybrid application is a more cost-effective seismic measure and has excellent performance during pulse ground motions. But the seismic response of near-fault long-span cable-stayed bridges more serious as the ratio of $\mathrm{PGV}$ to $\mathrm{PGA}$ increasing, so the ECDs are not suitable for controlling the displacement of the girder-tower. $\mathrm{Li}$ et al. [18] investigated the seismic design method for a kilometer-scale cable-stayed bridge under near-fault pulsetype uniform earthquake action. The nonlinear dynamic analysis of three seismic systems (i.e., the ECD, the fluid viscous damper (FVD), and the combination device of the two were used between the towers and beams, resp.) was carried out. Based on the target damping rate, if the span is more than $1 \mathrm{~km}$, the hybrid seismic system has a better effect, while if the span is more than 500 meters and less than $1 \mathrm{~km}$, the ECDs system is suitable [19]. And under pulse-type nonuniform earthquake action, VDs' reduction efficacy of bending moment at the tower bottom is even poorer than that of the elastic connection device [20]. The above review shows that the ECDs can also effectively reduce the displacement response at the girder end of a cable-stayed bridge under earthquakes but may disadvantageously increase the internal force response of the main tower.

Although the viscous damper has a better effect on internal force control, it is complicated to install and expensive. As the girder-tower displacement target, the ECDs have more effect. Zhang and Liu [21] proposed the residual error method between CDFs based on strain monitoring data and Zhang et al.'s [22] research on the Wiener process can assist in verifying both the pros and cons of the two methods, VD and ECDs, to a certain extent. In this paper, to investigate the seismic performance of double-tower cablestayed bridges with different seismic structural systems, the best suitable seismic system for the long-span cable-stayed bridge with double-tower under strong uniform earthquake is selected.

\section{Prototype Bridges}

2.1. Structural Configuration. The prototype bridge considered in this paper is a long-span cable-stayed bridge with double towers. The main span is $680 \mathrm{~m}$, and the overall length of the bridge is $1280 \mathrm{~m}$ with steel box girders and 
seven spans $(60+90+150+680+150+90+60 \mathrm{~m})$, as shown in Figure 1. The main girder is a single-box threechamber streamlined flat monolithic steel box with a girder height of $3.5 \mathrm{~m}$ and a width of $30.6 \mathrm{~m}$, as shown in Figure 2. The main tower is a concrete structure with 220 meters above the tower seat and 21 pairs of cable-stayed cables on both sides; compare Figure 3 (if the profiled steel sheetingconcrete bridge deck is considered, the relevant research of Gao et al. [23] can be referred to).

2.2. Structural Configuration. According to the Guidelines for Seismic Design of Highway Bridges [24], the category A seismic fortification will be considered for the bridge, which indicates that the bridge shall remain operational with limited postearthquake damage subjected to an E2 earthquake action. According to the three E2 seismic time history inputs provided in this article, the acceleration response spectrum is in good agreement with the designed acceleration response spectrum. E2-2, the seismic wave with the largest seismic response, was selected for conclusion analysis. The seismic input as shown in Figure 4 will be used in the following analyses "Fujian Earthquake and Geology Engineering Reconnaissance Institute, Minjiang Bridge Engineering Site Seismic Safety Evaluation Report [25]", which is obtained based on the in situ geological survey and corresponds to an exceeding probability of $4 \%$ in 100 years. The ground acceleration record in Figure 4 is categorized as an E2 earthquake action. Both the longitudinal and the vertical directions will be considered for the seismic load, and the vertical value is $50 \%$ the longitudinal one according to Fan and Ye [26].

\section{Dynamic Nonlinear Modelling}

3.1. Modelling the Upper Structure. The finite element (FE) model for the bridge is established based on the FE software package SAP2000, where the spatial beam element is used to simulate the steel girder (cf., Figure 2). The influence of the rotational inertia momentum due to girder mass is also incorporated. The cable is modelled by the beam element with the bending stiffness neglected. The sag effect of the cable is considered by using an equivalent Young's modulus. The RC elastic-plastic beam-column element is assigned for the main tower and the piers considering the plastic deformation under strong earthquake actions. Taking into account the elastic-plastic characteristics of RC structures, the generalized force distribution of the beam-column element is shown in Figure 5, in which $P$ represents the axial force, $Q_{y}$ and $Q_{z}$ represent, respectively, the shears in the $y$ and $z$ directions, $T$ presents the torsion, and $M_{y}$ and $M_{z}$ present, respectively, the moments in the $y$ and $z$ directions. The axial normal stress is generated by $P, M_{y}$, and $M_{z}$, and the transverse shear stress is generated by $Q_{y}, Q_{z}$, and $T$. Furthermore, the following assumptions apply to the beamcolumn element:

(1) The linear-elastic ideal-plastic moment-curvature relationship is used
(2) The shear and torsion strengths are sufficient to prevent the structure from brittle failure

(3) The yielding axial force and moment are independent of shear stress and can be determined by the normal stress distribution of the section

(4) The three-dimensional standard yield surface of the axial force and moment can be explicitly expressed (to be discussed later in detail)

(5) The potential plastic deformation only occurs at the end of the element beam, while the nodes between different elements remain elastic without considering the length of the plastic zone

(6) This section may be divided by subheadings. It should provide a concise and precise description of the experimental results, their interpretation, and the experimental conclusions that can be drawn

The relationship between the axial force and moment for the RC structures is expressed with the help of the yield surface as follows:

$$
f\left(\widetilde{P}_{u}, \tilde{M}_{y u}, \tilde{M}_{z u}\right)=1,
$$

where $f()$ is the yield surface function, as detailed in Figure 6, and

$$
\begin{gathered}
\widetilde{P}_{u}=\frac{P_{u}}{P_{0}}, \\
\tilde{M}_{y u}=\frac{M_{y u}}{M_{y 0}} \\
\tilde{M}_{z u}=\frac{M_{z u}}{M_{z 0}},
\end{gathered}
$$

in which $P_{u}$ represents the uniaxial yield tension, $P_{0}$ represents the uniaxial yield pressure, $M_{y 0}$ represents the pure yield moment around $y$ direction, and $M_{z 0}$ represents the pure yield moment about the $z$ direction.

3.2. Modelling the Supporting Connections. The prototype bridge considered in this paper is a semifloating system, with a longitudinal sliding bearing (transverse restraint) and a bidirectional sliding bearing installed between the main tower and the girder and piers. Furthermore, a transverse wind-resistant bearing is also equipped between the tower and the girder to restrain the transverse displacement. Sliding supports are used between the main tower, the tower beam, and the auxiliary pier to simulate the hinged longitudinal constraint, and the base of the main tower and pier shall be made of steel plate, which shall be connected with the table board of the shake table with fixed steel plate and bolts, and shall be fixed. The layout of the connection structures is shown in Figure 7.

In the FE model, the boundary conditions for these connections are shown in Table 1 , where $\Delta x, \Delta y$, and $\Delta z$ represent, respectively, the displacements along the longitudinal, vertical, and transverse directions of the bridge, and $\theta x, \theta y$, and $\theta z$ represent, respectively, the rotational angles 


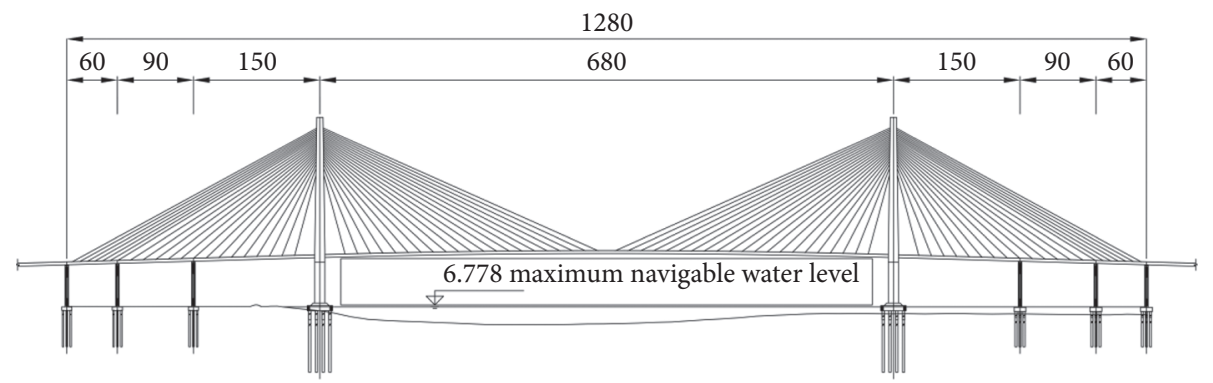

Figure 1: The overall layout of the double-tower cable-stayed bridge (unit: m).

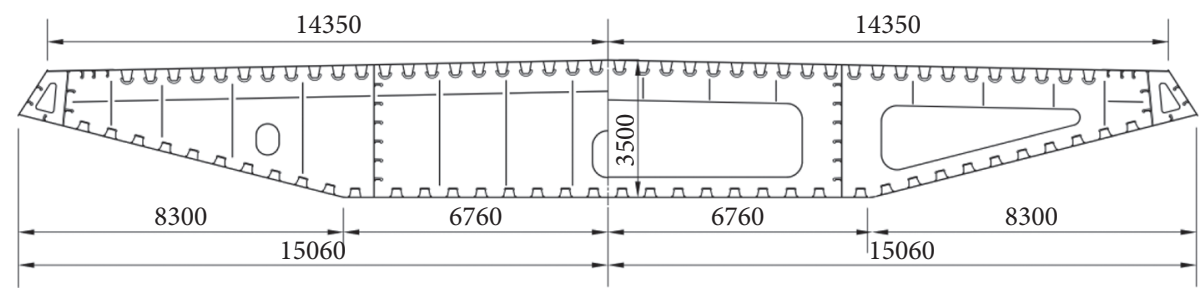

Figure 2: Cross-section of the steel box girder (unit: $\mathrm{m}$ ).

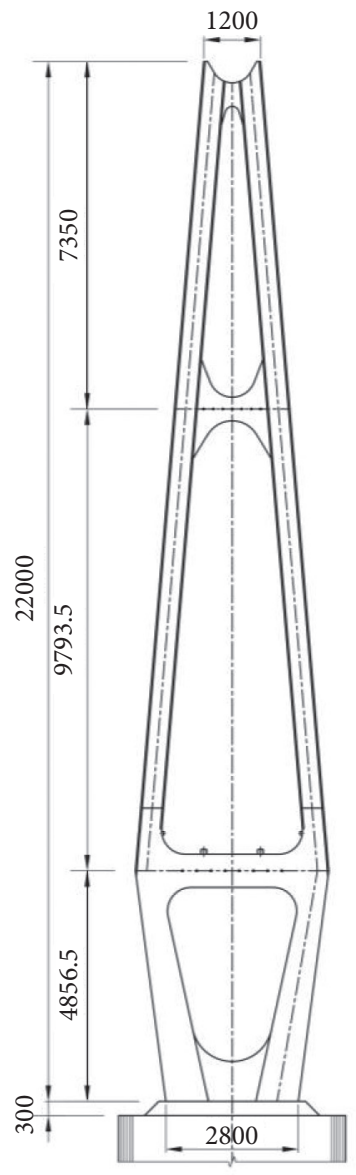

Figure 3: The structural layout of the main tower (unit: m).

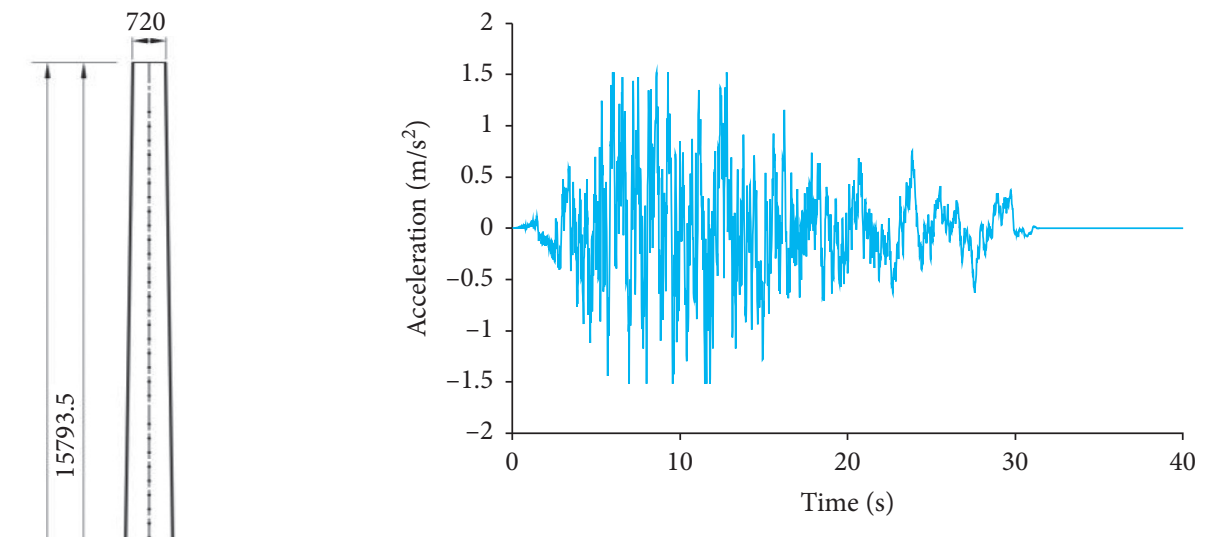

Figure 4: Ground acceleration record (adopted from "Fujian Earthquake and Geology Engineering Reconnaissance Institute, Minjiang Bridge Engineering Site Seismic Safety Evaluation Report” [24]).

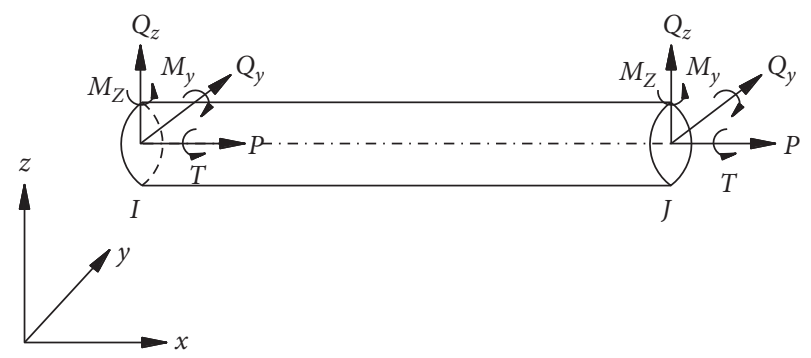

FIgURE 5: Force distribution of beam-column elements. 


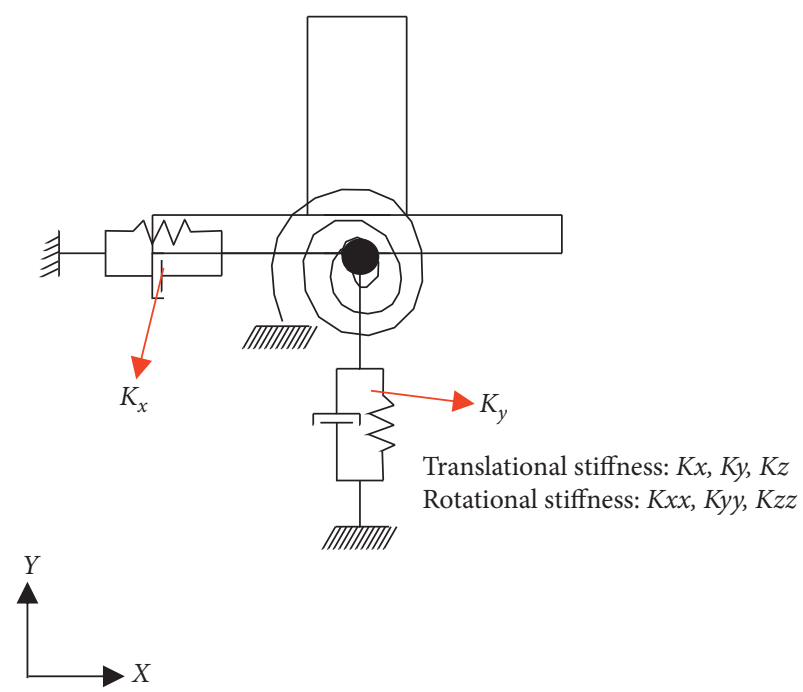

(a)

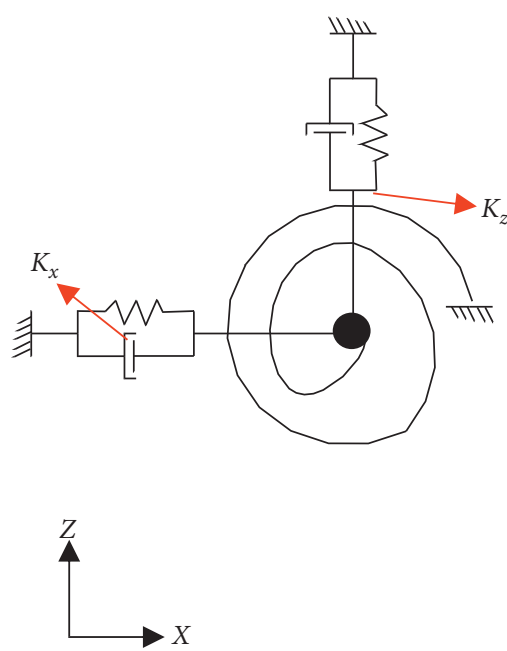

(b)

FIGURE 6: Six-spring model of the pile foundation: (a) elevation and (b) plan view.

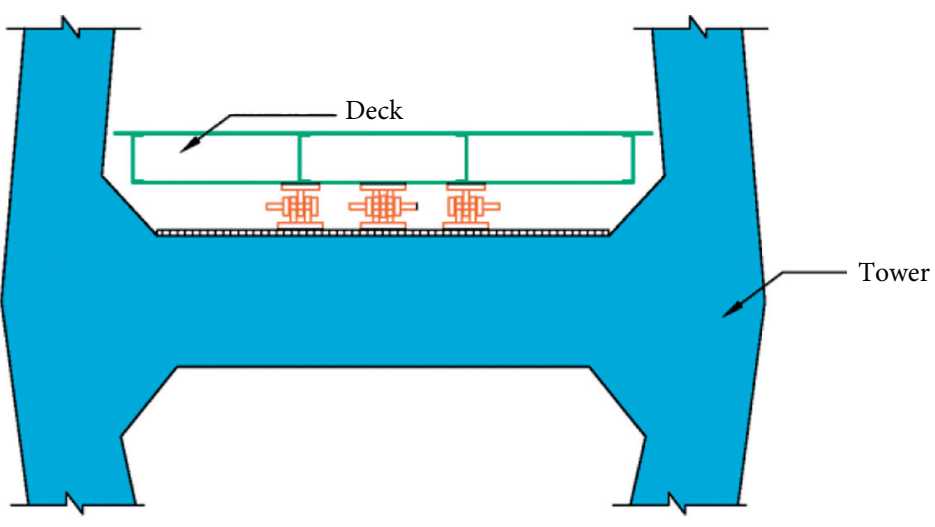

(a)

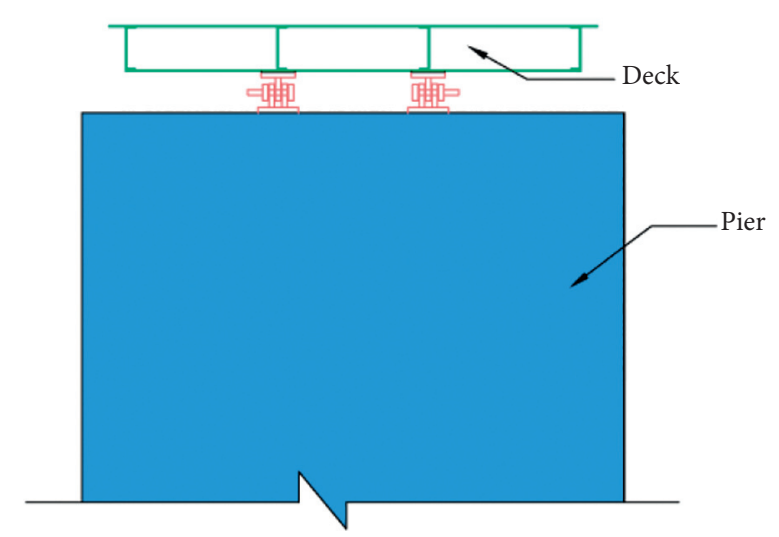

(b)

Figure 7: The layout of the connection structures. (a) The connection structures between beam and piers. (b) The connection structures between beam and pylon.

TABLE 1: Boundary conditions in the FE model.

\begin{tabular}{lccccc}
\hline Connections & $\Delta_{x}$ & $\Delta_{y}$ & $\Delta_{z}$ & $\theta_{x}$ & $\theta_{y}$ \\
\hline Pier bottoms & 1 & 1 & 1 & $\theta_{z}$ \\
Connection between tower and girder & 0 & 1 & 1 & 1 & 1 \\
Connection between tower and piers & 0 & 1 & 1 & 1 & 0 \\
\hline
\end{tabular}

about the longitudinal, vertical, and transverse directions. In Table 1, 1 represents constrained and 0 represents released.
3.3. Modelling the Bridge Pile Foundation. A six-spring model is used to model the bridge pile foundation, including three translational springs (with stiffness of $K_{x}, K_{y}, K_{z}$ ) and 
three rotational springs (with rotational stiffness of $K_{x x}, K_{y y}$, $K_{z z}$ ), and, in Figure 6, the general formulas are shown:

$$
\begin{aligned}
K_{x} & =K_{y}=n P_{2}, \\
K_{z} & =n P_{2}, \\
K_{x x} & =P_{1} \sum_{i=1}^{N} y_{i}^{2}, \\
K_{y y} & =P_{1} \sum_{i=1}^{N} x_{i}^{2}, \\
K_{z z} & =P_{2} \sum_{i=1}^{N}\left(y_{i}^{2}+x_{i}^{2}\right),
\end{aligned}
$$

in which $P_{1}$ represents the vertical force generated at the stake tip when the unit longitudinal vertical displacement is generated at the stake tip. $P_{2}$ represents the horizontal force generated at the stake tip when the unit horizontal displacement is generated at the stake tip; $x_{i}$ and $y_{i}$ represent, respectively, the longitudinal and transverse distances of the $i^{\text {th }}$ root stake from the center point of the cushion cap; and $N$ is the number of stakes. $P_{1}$ and $P_{2}$ are determined by the $\mathrm{m}$ method.

3.4. Summary of the FE Modelling. A nonlinear three-dimensional finite element model is established for the whole bridge in SAP2000, as shown in Figure 8. The main tower, piers, and pile foundation of the bridge are all RC structures with Poisson's ratio of 0.2 and a mass density of $2549 \mathrm{~kg} / \mathrm{m}^{3}$. Young's modulus is $34.5 \mathrm{GPa}, 32.5 \mathrm{GPa}$, and $30.0 \mathrm{GPa}$, respectively, for the main tower, piers, and pile foundation. For the steel girder and the stay cables, Poisson's ratio is 0.3 , and the mass density is $7850 \mathrm{~kg} / \mathrm{m}^{3}$. Young's modulus is 20.6 $\mathrm{GPa}$ and $19.5 \mathrm{GPa}$, respectively, for the steel girder and the stay cables. These configurations are representative of a realistic long-span cable-stayed tower bridge as introduced in "Modelling the Upper Structure" section.

\section{Seismic Behaviors Associated with Two Types of Seismic Mitigation Systems}

In order to compare the effects of the two types of seismic mitigation systems on the bridge seismic behavior, this section analyzes the dynamic characteristics and seismic response of the double-tower cable-stayed bridge. The main control objective is to reduce the longitudinal displacement of the main girder of the cable-stayed bridge under earthquake action. In the finite element modeling, the structure itself is in the elastic range, and the maximum displacement is controlled to be less than the limit without structural damage.

4.1. Introduction of Two Types of Seismic Mitigation Systems. The cylinder VDs are often used on bridges. The internal structure and typical VDs are shown in Figure 9. The damping force provided by the VD mainly depends on the movement speed of the piston relative to the container. The damping force of the VDs is given by equation (4), as

$$
f=c_{a} \operatorname{sgn}(\dot{u})|\dot{u}|^{a},
$$

in which $c_{a}$ represents the damping coefficient, sgn $(\dot{u})$ represents the symbolic function, $\dot{u}$ represents the piston velocity, and $\alpha$ represents speed exponent.

The ECDs mainly include elastic cables and the laminate rubber bearing. The hysteretic force $F$ of an ECD is a linear function of the relative displacement between the tower and the girder; that is,

$$
F=K_{e} d
$$

in which $K_{e}$ represents the stiffness of the ECD. Under the seismic loads, installing ECDs between the tower and the girder for the cable-stayed bridge can increase the structural stiffness and mitigate the girder-end displacement.

The seismic mitigation effects of both types of constraint systems (i.e., damping-based system and elastic restraint system) will be compared in the following. For both seismic mitigation systems, the installation scheme is shown in Figure 10.

In order to compare the damping effect of the damping restraint system and the elastic restraint system, the setting of the viscous damper and the elastic cable in the background project is as follows: the scheme of arranging the damper is to arrange 2 longitudinal viscous dampers between the lower beam of each main tower and the main beam. The arrangement of elastic cables is to set 2 elastic cables between the lower beam and the main beam of each main tower. Because the bridge is a symmetrical structure, only a single damper or elastic cable is used for research.

In the FE model, the VD is represented by a nonlinear damper element, and the ECD is modelled by considering the stiffness $K_{e}$ in equation (5); the stiffness $K_{e}$ is $2.5 \times 10^{4} \mathrm{kN} / \mathrm{m}$ for the ECDs. The VD damping coefficient is set as $3000 \mathrm{kN}(\mathrm{m} / \mathrm{s})^{-\alpha}$, and the damping exponent $\alpha$ equals 0.4 (cf. equation (4))

4.2. Comparison between the Dynamic Characteristics. The first ten (10) orders of the bridge seismic characteristics are shown in Table 2, including the natural vibration frequencies associated with the first-order torsion of the main girder and the corresponding modal shapes. Since the damping has a negligible effect on the natural frequency, the bridge frequency with VD installed is approximately the same as that without installing VD devices.

It can be seen from Table 2 that the main difference between the bridge frequency with VD installed and that with ECD installed is associated with the first and the sixth orders of vibration modes. Note that the first-order mode is dominated by the longitudinal drift of the main girder. Using the ECD, the first-order vibration frequency of the bridge increases from $0.1106 \mathrm{~Hz}$ to $0.2110 \mathrm{~Hz}$, implying that the longitudinal rigidity of the bridge is significantly improved with ECD. For the sixth-order mode where the antisymmetric vertical bending of the main girder 


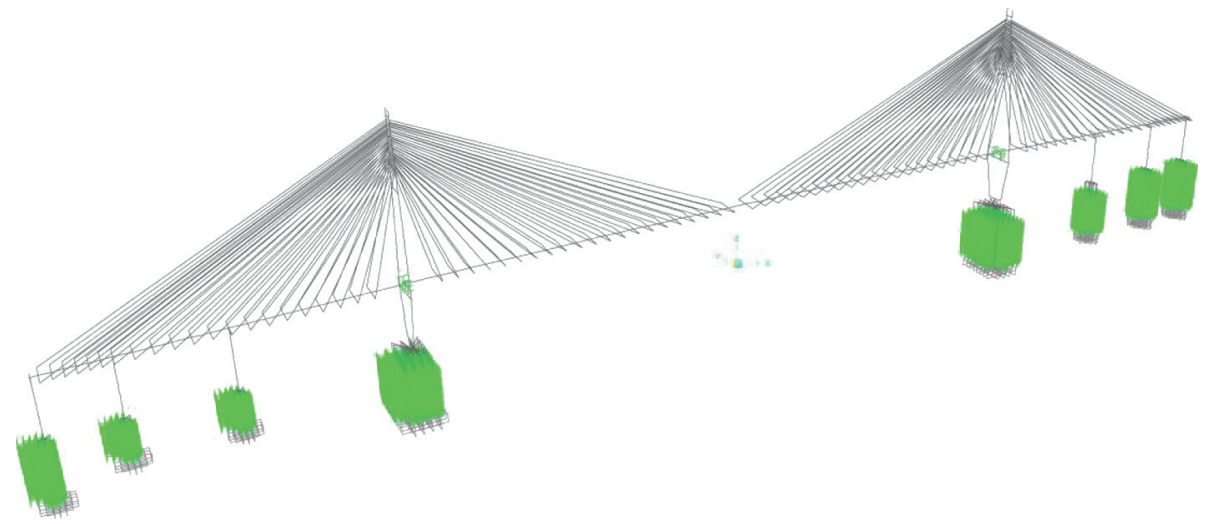

Figure 8: FE model of the full bridge using SAP2000.

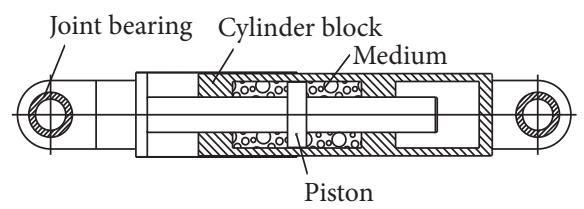

(a)

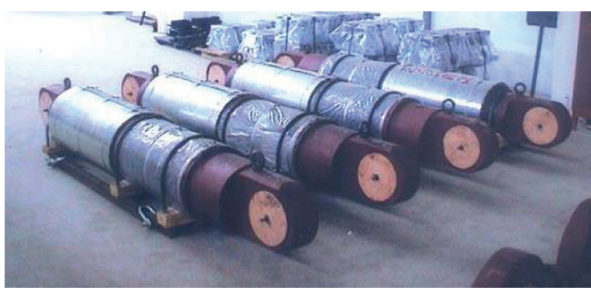

(b)

FIGURE 9: Illustration of VDs. (a) Illustration of the internal structure. (b) Photo of VDs.

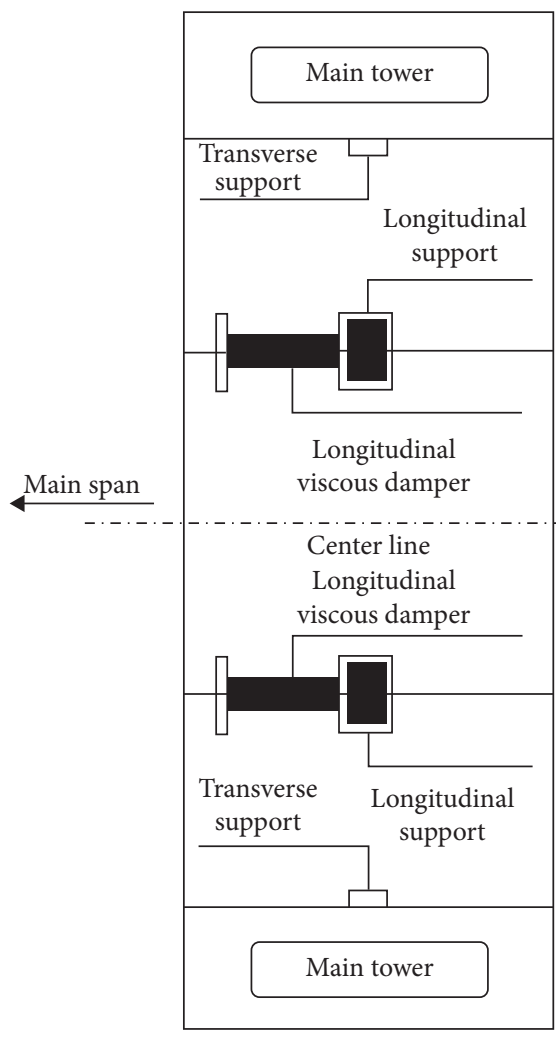

(a)

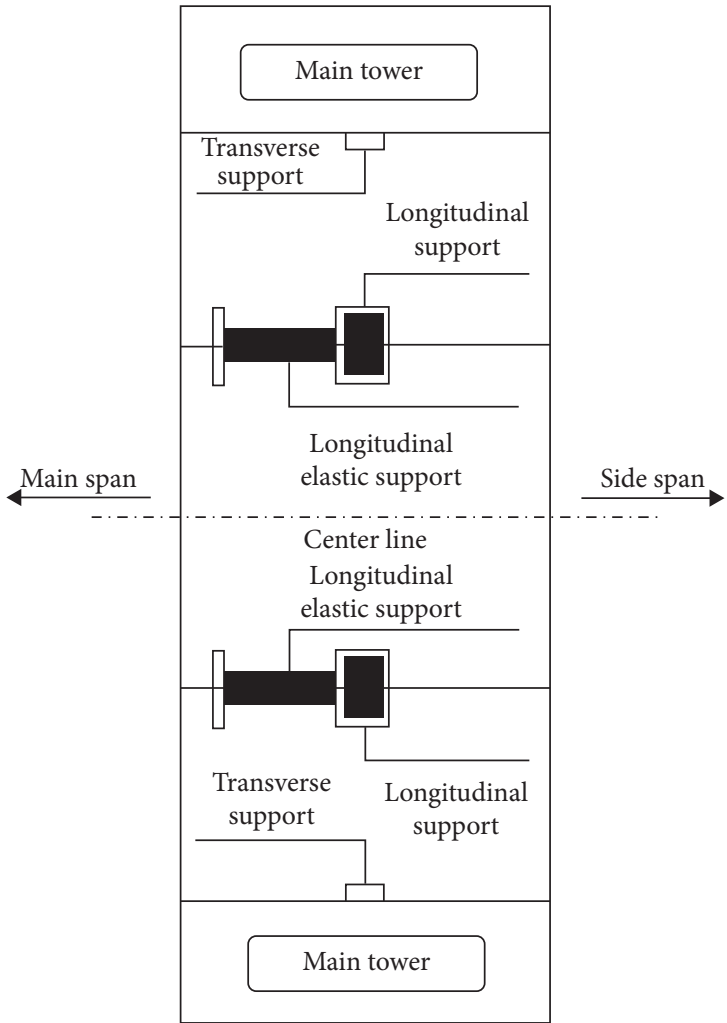

(b)

FIGURE 10: Installation scheme of the seismic mitigation devices. (a) VD. (b) ECD. 
TABLE 2: Vibration frequencies and the corresponding modal shapes of the bridge.

\begin{tabular}{|c|c|c|c|c|}
\hline \multirow[t]{2}{*}{ Order } & \multicolumn{2}{|c|}{$\begin{array}{l}\text { Frequency } \\
\quad(\mathrm{Hz})\end{array}$} & \multirow[t]{2}{*}{ Mode description } & \multirow[t]{2}{*}{ Modal shape } \\
\hline & VD & ECD & & \\
\hline 1 & 0.1106 & 0.2110 & Longitudinal drift of main girder & 111 \\
\hline 2 & 0.2269 & 0.2269 & The $1^{\text {st }}$-order symmetric transverse bending of the main girder & $\Leftrightarrow$ \\
\hline 3 & 0.2754 & 0.2757 & The $1^{\text {st }}$-order symmetric longitudinal bending of the main girder & \\
\hline 4 & 0.2925 & 0.2925 & The reverse side bending of the two main towers & exmannm \\
\hline 5 & 0.2978 & 0.2978 & The same side bending of the two main towers & $\Leftrightarrow \quad 1=$ \\
\hline 6 & 0.3625 & 0.3744 & The $1^{\text {st }}$-order antisymmetric vertical bending of the main girder & \\
\hline 7 & 0.4555 & 0.4555 & The longitudinal vibration of pier \#7 & \\
\hline 8 & 0.4745 & 0.4748 & The longitudinal vibration of pier $\# 0$ & \\
\hline 9 & 0.5141 & 0.5161 & The $2^{\text {nd }}$-order symmetric longitudinal bending of the main girder & \\
\hline 10 & 0.5658 & 0.5658 & $\begin{array}{l}\text { The } 1^{\text {st }} \text {-order symmetric transverse bending of the main girder }+ \text { transverse } \\
\text { bending of piers } \# 0, \# 1 \text {, and } \# 2\end{array}$ & $\Pi$ \\
\hline
\end{tabular}

dominates, the bridge frequency increases from $0.3625 \mathrm{~Hz}$ to $0.3744 \mathrm{~Hz}$ if installing ECD, with a weakened difference compared with the first-order mode.

4.3. Seismic Response and Mechanism Analysis. Because the longitudinal uniform seismic excitation has antisymmetric load characteristics and the double-tower cable-stayed bridge is generally a symmetrical structure, its structural seismic response has the characteristics of antisymmetric. Under uniform longitudinal earthquakes, the main beam girder-end displacement of the twin-tower cable-stayed bridge, the bottom moment of the main tower, and the shear force are mainly caused by the first-order longitudinal drift of the main beam, the low-order antisymmetric vertical bending mode of the main beam, and the high mode. Among them, the transverse seismic wave input is not considered.

The comparison of the internal forces in the longitudinal direction and the displacements of the cable-stayed bridge under the earthquake action with different seismic mitigation systems (VD and ECD) is presented in Table 3. Furthermore, the seismic mitigation ratio of the two systems is given in Table 4, where the mitigation ratio is computed as (mitigated peak response-peak response without mitigation)/peak response without mitigation $\times 100 \%$.

It is seen from Table 3 that the maximum moment at the tower base is less than the yielding moment $\left(3.648 \times 10^{6} \mathrm{kN} \cdot \mathrm{m}\right)$ without seismic mitigation measures, implying that the bridge is within the elastic range with both types of device.

When the ECD is used, the longitudinal displacement at the main girder end and that at the main tower end are reduced compared with the case with no mitigation device installed. For example, the longitudinal displacement at the girder end decreases from $1.414 \mathrm{~m}$ to $0.951 \mathrm{~m}$. The seismic mitigation ratios associated with the longitudinal displacements at the girder end and the tower end are $32.74 \%$ and $28.10 \%$, respectively. However, the base moment at the main tower is only slightly reduced, and the base shear at the main tower is disadvantageously increased.

For a VD-based restraint system, the longitudinal displacements at both the main girder end and the tower end are also reduced. Furthermore, the seismic mitigation ratios associated with the base shear and base moment at the tower are $18.69 \%$ and $19.15 \%$, respectively. This demonstrates that installing VD can significantly reduce the seismic response of the bridge in terms of both longitudinal displacements and internal forces.

To summarize, compared with the bridge without seismic mitigation devices, the longitudinal displacements at both the girder end and the tower end can be reduced by the two types of devices, and the VD-based system performs better because it not only results in a smaller displacement but also leads to a weaker internal force. On the other hand, the ECD has a relatively smaller efficiency in reducing the internal force (recall that it even increases the shear force at the tower base). As such, the seismic mitigation performance of VDs is better than that of ECDs.

In order to explain the mitigation mechanisms of ECDand VD-based systems, the seismic response spectra are plotted in Figure 11. By noting the fact that the first-order vibration mode of the bridge is dominated by the longitudinal drift of the main girder, if we let $T_{0}$ denote the natural period of the longitudinal drift mode, then $T_{0}$ would be located at the region where the acceleration response spectrum decreases with the period (cf., Figure 12(a)). 
TABLE 3: Comparison of longitudinal internal forces and displacements with different mitigation measures.

\begin{tabular}{lcccc}
\hline $\begin{array}{l}\text { Restraint } \\
\text { systems }\end{array}$ & $\begin{array}{c}\text { Longitudinal displacement at } \\
\text { girder end }(\mathrm{mm})\end{array}$ & $\begin{array}{c}\text { Longitudinal displacement at } \\
\text { tower top }(\mathrm{mm})\end{array}$ & $\begin{array}{c}\text { Base shear in tower } \\
(\mathrm{kN})\end{array}$ & $\begin{array}{c}\text { Base moment in the tower } \\
(\mathrm{kN} \cdot \mathrm{m})\end{array}$ \\
\hline Floating & 1.414 & 1.530 & $4.848 \times 10^{4}$ & $2.538 \times 10^{6}$ \\
system & 0.951 & 1.101 & $5.332 \times 10^{4}$ & $2.533 \times 10^{6}$ \\
ECD & 0.764 & 1.022 & $3.942 \times 10^{4}$ & $2.052 \times 10^{6}$ \\
VD & & & & \\
\hline
\end{tabular}

TABLE 4: Comparison of seismic mitigation ratios with different measures.

\begin{tabular}{|c|c|c|c|c|}
\hline Restraint systems & Longitudinal displacement at the girder end (\%) & $\begin{array}{l}\text { Longitudinal displacement } \\
\text { at the tower top (\%) }\end{array}$ & Base shear in tower & $\begin{array}{c}\text { Base moment in } \\
\text { tower }(\%)\end{array}$ \\
\hline ECD & 32.74 & 28.10 & $-9.98 \%$ & 0.32 \\
\hline VD & 45.97 & 33.20 & $18.69 \%$ & 19.15 \\
\hline
\end{tabular}

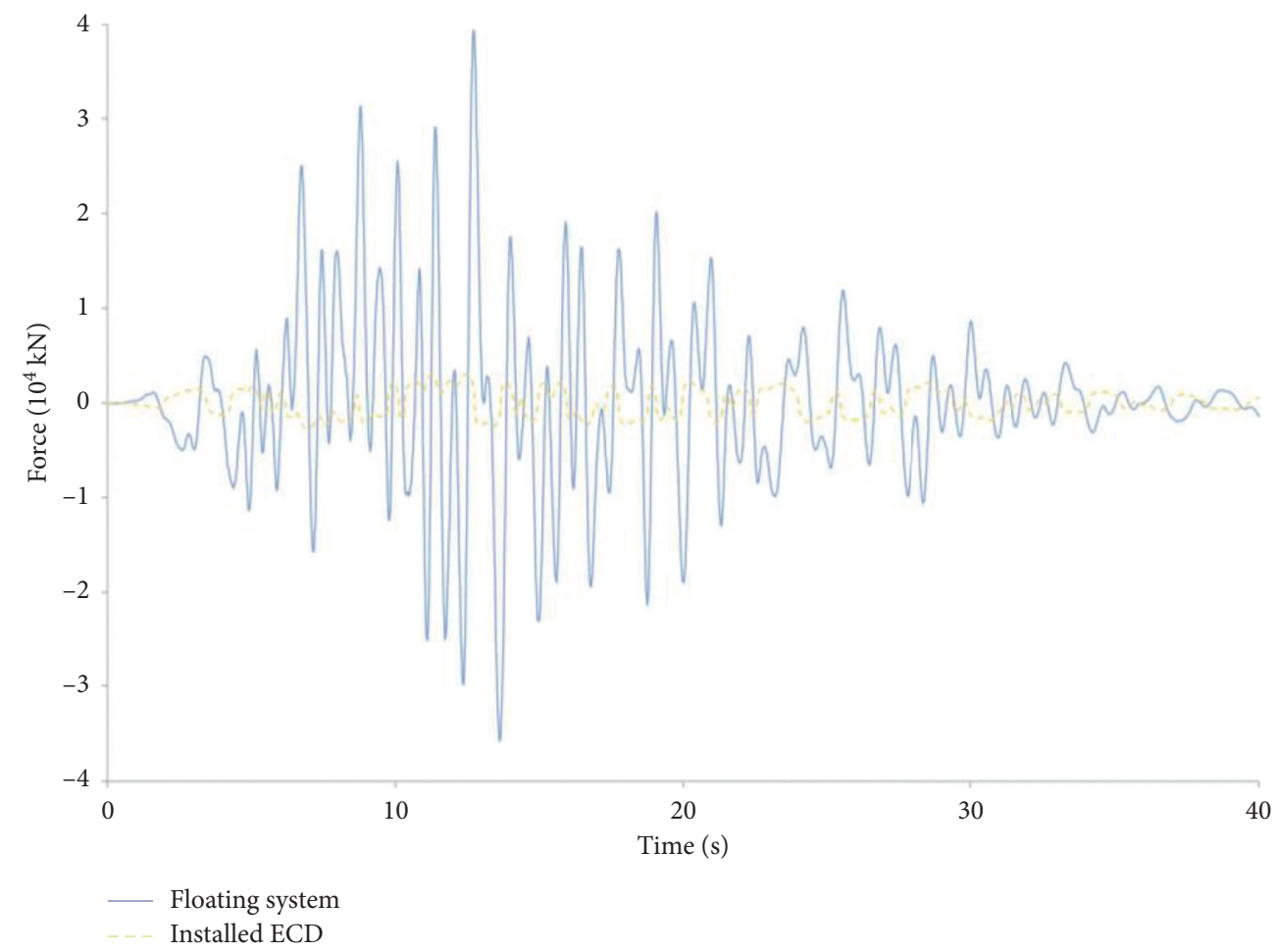

FIgURE 11: Time history analysis of the ECD tension and the tower base shear.

Therefore, extending the structural natural vibration period and/or increasing the structural damping ratio will weaken the acceleration and further the structural seismic response. In Figure 12(b), increasing the structural damping ratio will lead to a smaller displacement. However, increasing the vibration period (beyond $T_{0}$ ) will result in a greater structural displacement. Therefore, a greater structural damping ratio principally means a reduced seismic response in terms of both internal forces and displacements. However, a smaller vibration period, or equivalently a greater structural stiffness, will yield a smaller displacement but a greater internal force. This fact again indicates the advantage of VD-based mitigation systems compared with the ECD-based ones.
Because the main damage of a long-span cable-stayed bridge under earthquake is that the longitudinal displacement of the main girder longitudinal bridge is too large, which may cause a falling beam or damage the expansion joint, so it is necessary to discuss the longitudinal seismic response of the long-span cable-stayed bridge with the longstayed cable and it is very important. For details, please refer to Jia et al.'s related research on the pounding characteristics between beams and the reasonable interval length of main beams under different site conditions [27-30]. The author discusses the effects of different shock absorption parameters, and lateral analysis is also in further experimental research. For more, refer to Xu et al. [31]. 


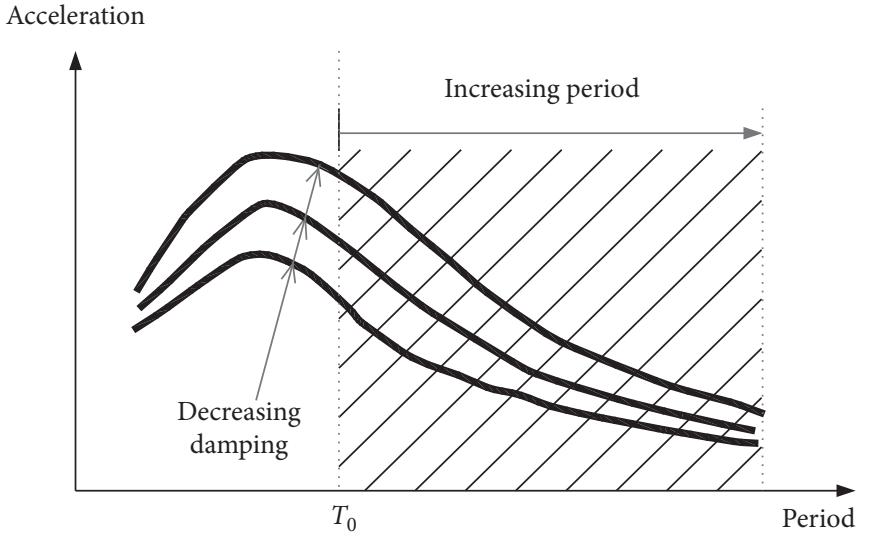

(a)

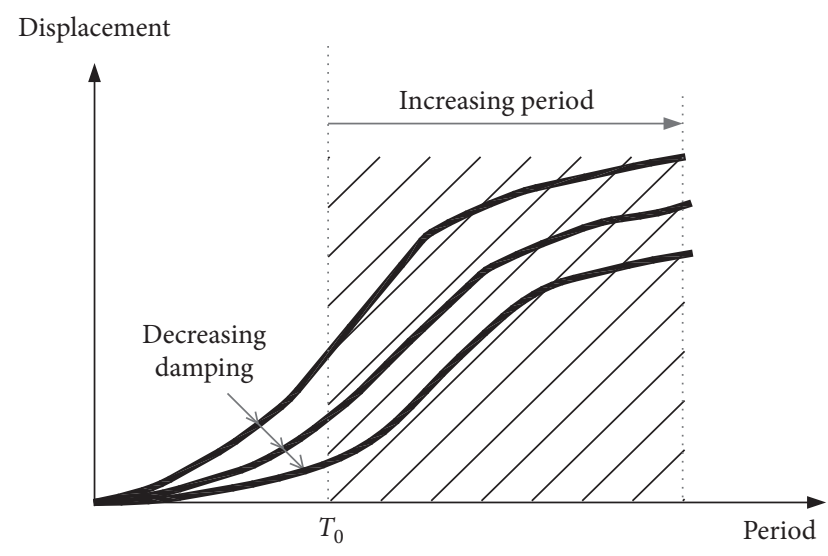

(b)

FIGURE 12: Illustration of the acceleration and displacement response spectra. (a) Acceleration response spectrum. (b) Displacement response spectrum.

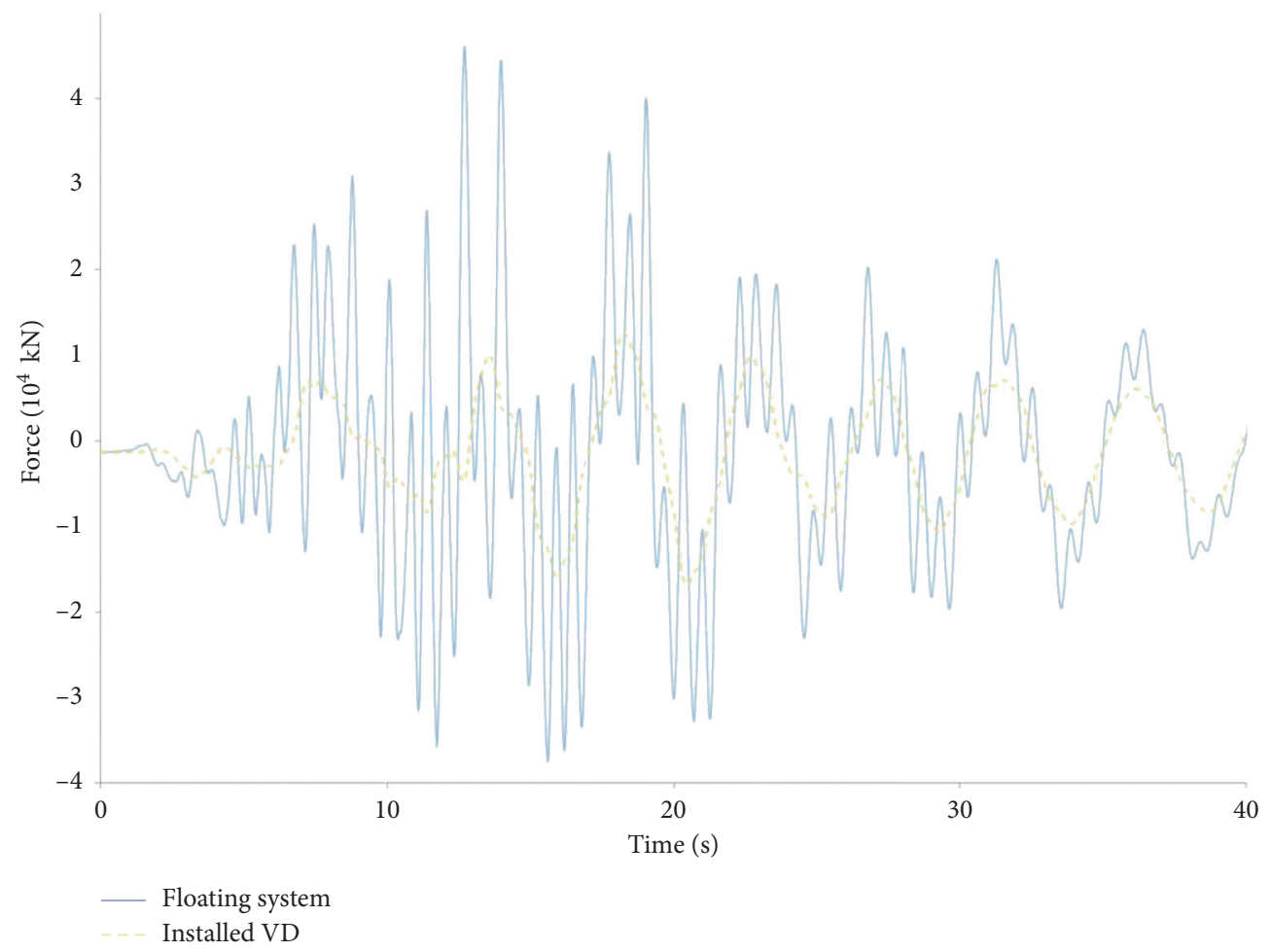

FIGURE 13: Time history analysis of the VD damping force and the tower base shear.

To achieve further insight into the seismic mitigation mechanism of both types of mitigation systems for the cablestayed bridge, the time history curves of structural seismic response are plotted in Figures 11 and 13 in terms of the shear force at the tower bottom. For comparison purpose, the ECD tensions and the damping forces (cf., equations (4) and (5)) are also presented in Figures 11 and 13, respectively. It can be seen that, overall, the damping force of VD is greater than that of ECD, implying that the VD-based system provides a more effective restraint to the bridge's seismic response.

In Figure 11, the impact of ECD on the tower shear force can be explained by Figure 14, which shows the two transmission paths of the seismic inertia force from the main girder to the foundation: the first is "girder-cable-towerfoundation" and the second is "girder-ECD-foundation." In terms of the latter, since the bridge longitudinal stiffness is enhanced with an ECD, the synchronization between the 


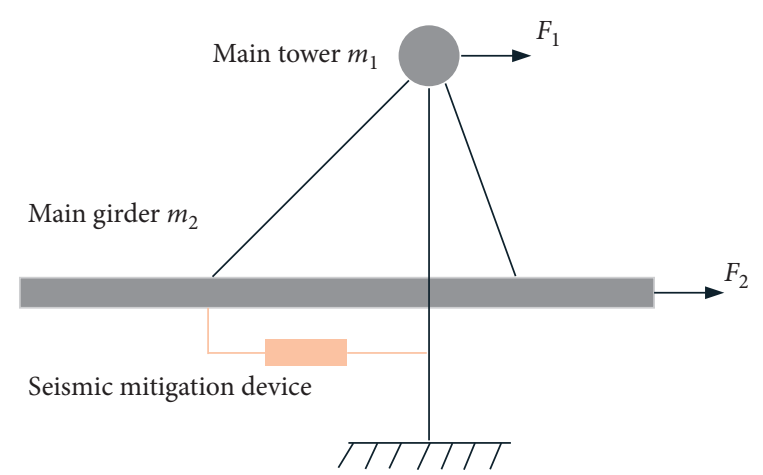

FIGURE 14: Force transmission from the girder to the foundation.

internal forces in the cables and the tower leads to a greater shear force at the tower bottom.

For the VD-based system as in Figure 14, since the VD does not affect the structural stiffness, there is a significant phase difference between the internal forces of the VD and the tower, which accounts for the smaller shear force at the tower bottom. Furthermore, as the arm of the VD's damping force is smaller than that of the tower shear force, the mitigation effect of VD on the moment at the tower bottom is enhanced compared with that of an ECD. This is consistent with the observations from Table 4. The comparison between Figures 11 and 13 again demonstrates that VDs have a better seismic mitigation performance than ECDs.

\section{Conclusions}

This paper has presented a comparison between the seismic mitigation effects of two types of devices on a long-span tower bridge, namely, VD and ECD. The dynamic characteristics of the bridge are analyzed through three-dimensional FE modelling of a prototype bridge. The following conclusions can be made from this paper.

(1) The main difference between the bridge dynamic characteristics associated with the ECD system and VD system is at the $1^{\text {st }}$-order and $6^{\text {th }}$-order vibrations. Compared with the case with no seismic mitigation device installed, when the prototype bridge is equipped with an ECD, the first-order vibration frequency increases from $0.1106 \mathrm{~Hz}$ to $0.2110 \mathrm{~Hz}$, implying that the longitudinal stiffness is remarkably enhanced.

(2) The longitudinal displacement at the bridge tower end and the girder end can be reduced by both ECDs and VDs. The mitigation effect is better when using VDs. Furthermore, VDs can also significantly weaken the internal force at the bridge tower, while the ECDs will disadvantageously increase the tower shear force. It is thus suggested that VD-based mitigation systems have a better performance than ECD-based systems for long-span tower bridges.

(3) From the transmission diagram of seismic inertia force of the main girder of a cable-stayed bridge, the inertia force of the main girder in the elastic constraint system is transmitted to the foundation partly by the cable through the upper tower and partly by the elastic cable or viscous damper through the lower tower. For the elastic constraint system, the elastic constraint increases the longitudinal stiffness of the beam, and the seismic horizontal force transmitted by the elastic cable is synchronized with the time travel curve of the internal force at the bottom of the main tower, so the shear force at the bottom of the tower is increased. For the damped constrained system, the longitudinal stiffness of the beam is not increased, and the horizontal seismic force of the beam body subjected to the damper is inversus proportional to the time travel curve of the internal force at the bottom of the main tower, with a phase difference. Therefore, the shear force at the bottom of the tower decreases, and the seismic power transmitted by the damper is smaller than the arm at the bottom of the tower, so the bending moment at the bottom of the tower is reduced more than the shear force. From the analysis of the damping mechanism, it can be found that a viscous damper has a good damping effect and is an ideal damping device.

(4) This article studies the assumption under the premise that the stiffness, quality, and damping of the cable-stayed bridge structure itself do not change significantly. The research conclusion is only applicable to the online elastic range of cable-stayed bridge structure itself and mainly studies the seismic response characteristics and damping effect of a long-span twin-tower cable-stayed bridge in longitudinal direction under the longitudinal seismic action, while the research on the damping of cablestayed bridge with different spans under the transverse seismic action remains to be further studied.

\section{Data Availability}

Some data, models, or codes generated or used during the study are available from the corresponding author upon request (SAP2000 modeling files and generated outputs).

\section{Conflicts of Interest}

The authors declare that they have no conflicts of interest.

\section{Acknowledgments}

This research was funded by the Natural Science Foundation of Fujian Province (Grant no. 2020J0113). The authors also acknowledge the help of Zhenzheng Fang, Ai Qi, and Zhen Lin for conducting shaking table tests.

\section{References}

[1] J. J. Guo, J. Zhong, X. Z. Dang, and W. C. Yuan, "Seismic responses of a cable-stayed bridge with consideration of uniform temperature load," Applied Sciences-Basel, vol. 6, no. 12, p. 408, 2016. 
[2] B. B. Soneji and R. S. Jangid, "Passive hybrid systems for earthquake protection of cable-stayed bridge," Engineering Structures, vol. 29, no. 1, pp. 57-70, 2007.

[3] M. D. Symans and M. C. Constantinou, "Semi-active control systems for seismic protection of structures: a state-of-the-art review," Engineering Structures, vol. 21, no. 6, pp. 469-487, 1999.

[4] J. Huang, W.-X. Zhang, L.-L. Zhao, and J.-J. Wang, "The influence of a bridge deck's relative height on the damping effect of a tower-girder elastic connecting device in cablestayed bridges," in Proceedings of the 4th International Conference on Civil Engineering and Urban Planning (CEUP), Bosen Acad Conf Solut Co. Ltd., Beijing, China, 2016.

[5] L. P. Xu, "Structural system analysis for super-long span cable-statyed bridges," Journal of Tongji University, vol. 31, no. 4, pp. 400-403, 2003.

[6] N. Makris and M. C. Constantinou, "Fractional-derivative Maxwell model for viscous dampers," Journal of Structural Engineering, vol. 117, no. 9, pp. 2708-2724, 1991.

[7] N. Makris, G. F. Dargush, and M. C. Constantinou, "Dynamic analysis of generalized viscoelastic fluids," Journal of Engineering Mechanics, vol. 119, no. 8, pp. 1663-1679, 1993.

[8] A. Ruangrassamee and K. Kawashima, "Seismic response control of a cable-stayed bridge by variable dampers," Journal of Earthquake Engineering, vol. 10, no. 1, pp. 153-165, 2006.

[9] J. Zhu, W. Zhang, K. F. Zheng, and H. G. Li, "Seismic design of a long-span cable-stayed bridge with fluid viscous dampers," Practice Periodical on Structural Design and Construction, vol. 21, no. 1, p. 11, 2016.

[10] F. Ferreira and L. Simoes, "Optimum design of a controlled cable-stayed footbridge subject to a running event using semiactive and passive mass dampers," Journal of Performance of Constructed Facilities, vol. 33, no. 3, 2019.

[11] W.-L. He and A. K. Agrawal, "Passive and hybrid control systems for seismic protection of a benchmark cable-stayed bridge," Structural Control and Health Monitoring, vol. 14, no. 1, pp. 1-26, 2007.

[12] L. Lu and J. Z. Li, "Study on vibration control effect of viscous dampers for rail-cum-road cable-stayed bridge during earthquake, train braking and running," Engineering $\mathrm{Me}$ chanics, vol. 32, no. 12, pp. 139-146, 2015.

[13] A. J. Ye and L. C. Fan, "Seismic response reduction of a superlong-span cable-stayed bridge by adding," Dampers Journal of Tongji University (Natural Science), vol. 7, pp. 859-863, 2006.

[14] C. Y. Jiao, J. Z. Li, and T. B. Peng, "Effects of different connecting styles between towers and deck on seismic responses of a long-span cable-stayed bridge," Journal of Virbation and Shock, vol. 28, no. 10, pp. 179-184, 2009.

[15] H.-E. M. Ali and A. M. Abdel-Ghaffar, "Seismic energy dissipation for cable-stayed bridges using passive devices," Earthquake Engineering \& Structural Dynamics, vol. 23, no. 8, pp. 877-893, 1994.

[16] M. J. Wesolowsky and J. C. Wilson, "Seismic isolation of cable-stayed bridges for near-field ground motions," Earthquake Engineering \& Structural Dynamics, vol. 32, no. 13, pp. 2107-2126, 2003.

[17] W. C. Yuan and X. W. Qu, "Application analysis of seismic isolation devices on longitudinal seismic response of floating system cable-stayed bridge," Journal of Tongji University. Natural Science, vol. 43, no. 2, pp. 199-204, 2015.

[18] Y. Li, W. M. Yan, Y. J. Chen, and E. Guo, "Seismic response analysis and control of long-span cable-stayed bridges under near-fault earthquakes," Journal of Disaster Prevention and Mitigation Engineering, vol. 30, no. 5, pp. 479-486, 2010.
[19] Z. F. Han and A. J. Ye, "Research on seismic-reduction for cable-stayed bridges over kilometers under pulse earthquake action," Journal of Civil, Architectural \& Environmental Engineering, vol. 40, no. 4, pp. 111-120, 2018.

[20] Z. F. Han and A. J. Ye, "Research on the seismic reduction of cable-stayed bridges over kilometers under pulse-type nonuniform earthquake action," Journal of Earthquake Engineering and Engineering Vibration, vol. 38, no. 2, pp. 184-193, 2018.

[21] S. Zhang and Y. Liu, "Damage detection of bridges monitored within one cluster based on the residual between the cumulative distribution functions of strain monitoring data," Structural Health Monitoring, vol. 19, no. 6, p. 1764, 2020.

[22] Z. Zhang, X. Liu, Y. Zhang, M. Zhou, and J. Chen, “Time interval of multiple crossings of the Wiener process and a fixed threshold in engineering," Mechanical Systems and Signal Processing, vol. 135, Article ID 106389, 2020.

[23] Q. Gao, Z. Dong, K. Cui, C. Liu, and Y. Liu, "Fatigue performance of profiled steel sheeting-concrete bridge decks subjected to vehicular loads," Engineering Structures, vol. 213, Article ID 110558, 2020.

[24] Earthquake and Geology Engineering Reconnaissance Institute, Minjiang Bridge Engineering Site Seismic Safety Evaluation Report, Earthquake and Geology Engineering Reconnaissance Institute, Fuzhou, China, 2010.

[25] Ministry of Communication of China, Guidelines for Seismic Design of Highway BridgesBeijing: People's Communications Press, Beijing, China, 2008.

[26] L. Fan and A. Ye, The Seismic Design of Long-Span Bridges, China Communications Publishing and Media Management Co., Beijing, China, 2001.

[27] H.-Y. Jia, D.-Y. Zhang, S.-X. Zheng, W.-C. Xie, and M. D. Pandey, "Local site effects on a high-pier railway bridge under tridirectional spatial excitations: nonstationary stochastic analysis," Soil Dynamics and Earthquake Engineering, vol. 52, pp. 55-69, 2013.

[28] D.-Y. Zhang, H.-Y. Jia, S.-X. Zheng, W.-C. Xie, and M. D. Pandey, "A highly efficient and accurate stochastic seismic analysis approach for structures under tridirectional nonstationary multiple excitations," Computers \& Structures, vol. 145 , pp. $23-35,2014$.

[29] H. Jia, J. Zhao, Xi Li, L. Li, and S. Zheng, "Probabilistic pounding analysis of high-pier continuous rigid frame bridge with actual site condition," Earthquakes and Structures, vol. 5, no. 2, pp. 193-202, 2018.

[30] H.-Y. Jia, X.-L. Lan, S.-X. Zheng, L.-P. Li, and C.-Q. Liu, "Assessment on required separation length between adjacent bridge segments to avoid pounding," Soil Dynamics and Earthquake Engineering, vol. 120, pp. 398-407, 2019.

[31] L. Xu, K. Bi, J.-F. Gao, Y. Xu, and C. Zhang, "Analysis on parameter optimization of dampers of long-span doubletower cable-stayed bridges," Structure and Infrastructure Engineering, vol. 16, no. 9, pp. 1286-1301, 2019. 